\title{
Plasma Cell Myeloma by RISS Stage
}

National Cancer Institute

\section{Source}

National Cancer Institute. Plasma Cell Myeloma by RISS Stage. NCI Thesaurus. Code C141393.

A staging system for plasma cell myeloma based on the Revised International Staging System (RISS) criteria. This staging system does not apply to smoldering multiple myeloma (no AJCC staging system), monoclonal gammopathy of undetermined significance (no AJCC staging system), and Waldenstrom macroglobulinemia (no AJCC staging system). (from AJCC 8th Ed.) 